\title{
Occupational exposure to pesticides towards the danger of childhood leukemia in China.
}

\author{
Chun-Mei Yu*
}

Department of Pediatrics, Maternal and Child Health Care of Zaozhuang, Zaozhuang City, 277102, Shandong province, PR China

\begin{abstract}
The association between the higher occurrence of pediatric leukemia and maternal exposure to residential or occupational pesticides is a debatable subject, especially in agricultural country like China. This study evaluates the association between exposure of mothers to home and occupational pesticides and likelihood of pediatric leukemia. A questionnaire-based survey was conducted in main hospitals of Zhengzhou city, China, between September 2014 and October 2015 and children and mothers $(n=1203)$ from oncology (cases; $n=390)$ and orthopedic department (controls; $n=813$ ) were enrolled. The Odds Ratio (OR) for correlation between incidence of leukemia and professional home pest control applications during pregnancy and post-childbirth were 1.8 [95\% Confidence Interval (CI), 1.2-2.8] and 1.3 [95\% CI, 1.1-2.4], respectively. The OR for association between incidence of leukemia and garden pesticide exposure during pregnancy was 2.3 [95\% CI, 0.8-7.2] and during childhood was 1.23 [CI, 1.1-2.7], respectively. These results suggest that possible pesticide exposure during pregnancy is related to increased likelihood of leukemia in children and mothers are advised to avoid exposure to pesticides during pregnancy.
\end{abstract}

Keywords: Childhood leukemia, Pesticides, Acute lymphoblastic, Leukemia, Insecticides.

Accepted on July 18, 2016

\section{Introduction}

Leukemias are neoplastic disorders of white blood cells marked by genetic and chromosomal abnormalities that prevent blood cells to achieve their ultimate functional form $[1,2]$. Leukemia accounts for around $30 \%$ of total malignant tumors and is common in children around the world. Acute leukemia constitutes approximately $95 \%$ of leukemias and Acute Lymphoblastic Leukemia (ALL) is the most frequently reported pediatric leukemia, with approximately $80 \%$ of total leukemia cases in children [3]. The incidence rate of ALL between 1991 and 1994 was 59 events per million children aged below 5 years. The highest incidence rate was observed in children aged 2-6 years, with $>80$ events occurring each year per million children aged 3-4 years [4,5], and the rate declined with age. Based on this pattern, researchers believe that leukemia development occurs after both the first chromosomal translocation, which usually occurs during embryofetal development, and the second mutation, which occurs post-birth [6,7]. The etiology of ALL in children is considered different from that in adults and although ALL is common in children, it is rarer than most adult cancers. This makes ALL difficult to study epidemiologically and very few definitive likelihood factors are established, such as chemotherapeutic agents, ionizing radiations, and genetic/chromosomal abnormalities [8]. Based on limited evidence that is currently available, it is hypothesized that childhood acute leukemia may be a consequence of interactions between genetic predisposition and environmental factors including chemotherapeutic agents and pesticides [9].

Data on carcinogenic potential of pesticide use are limited, and the association between the higher occurrence of pediatric leukemia and maternal exposure to residential or occupational pesticides is highly debated. In a Seattle-based study, higher urine concentrations of dimethyl and diethyl dialkylphosphate, organophosphorus pesticide metabolites, were reported in children whose parents were exposed to either garden or indoor pesticides [10]. Several studies have reported gestational exposure of pesticides to be the cause of various malignancies, including leukemia, Wilms' tumor, neuroblastoma, Ewing's sarcoma, soft-tissue sarcoma, non-Hodgkin's lymphoma, in children. Although these surveys lack conclusive evidence owing to non-specific pesticide exposure information, low number of participants, and potential for case-response bias, the risks reported by them are of greater magnitude than those noted for adults exposed to pesticides. This calls for attention to a possibility of children being more disposed to the carcinogenicity of pesticides [11,12]. Children in China, especially those living around treated agricultural lands, are overexposed to pesticide drift through ground application, overspray, or off-gassing [13]. We aimed to analyze the correlation between pesticide exposure in children and childhood acute leukemia. 


\section{Materials and Methods}

\section{Study design and study participants}

This was a questionnaire-based, case-control survey wherein retrospective data on mother's pesticide exposure preconception, during and/or post-pregnancy and child's exposure post-birth was recorded. The study was carried out in the main hospitals of Zhengzhou city, China, between September 2014 and October 2015. It was planned to report correlation between pediatric acute leukemia and the following 3 sources of pesticides: home insecticides use, garden pesticide use and occupational insecticide use. However, only few parents had occupational pesticide exposure and hence were not included in the final analysis.

One thousand two hundred and three children aged 3-12 years were recruited. Eligible cases $(n=390)$ were children from oncology department diagnosed with Leaukaemia. Controls $(n=813)$ were primarily recruited from orthopedic department of the hospital. All study participants recruited belonged to the same territory (excluding 7 cases and 4 controls). This was done to avoid bias and to ensure comparability between cases and controls with respect to socioeconomic class and rural/ urban statuses.

The mothers of all participants were interviewed personally by trained physicians using a standard questionnaire. The questions were related to parent's sociodemographic characteristics, their occupation and pesticide use, family history of cancer and autoimmune diseases, the child's medical history. Questions concerning pesticide exposure covered period before conception, during pregnancy, and from birth of the child until diagnosis. The pesticides covered were weed killers (herbicides), insecticides, and fungicides at home and in garden. The closed questions asked were "did you regularly use insecticides at home?", "did you use gardening chemicals/ fertilizers, weed killers, insecticides, fungicides yourself?"

\section{Data collection and results of analysis of exposure assessment}

The sample size of this study allowed determination of minimum odds ratio (OR) of 1.6, 1.9, and 2.2 for exposure frequency of $20 \%, 10 \%$, and $5 \%$, respectively, in controls. This frequency was similar to that of home $(21 \%$ and $29 \%$, respectively) and garden ( $1 \%$ and $5 \%$, respectively) insecticide use during pregnancy and during childhood. A sensitivity analysis was performed to assess the bias introduced by missing values. The ORs remained $>1$ when the missing data were all considered to be from the pesticide-exposed group. When the missing data were considered from unexposed group, the odds ratios were significant or almost significance: OR 2.0, 95\% CI 1.2-3.3, and OR 1.5, 95\% CI 0.9-2.5, respectively. In an unexpected event, if the missing data were from unexposed cases and exposed controls, the OR would be $1.2,95 \%$ CI $0.7-1.9$.

\section{Results}

\section{Study groups}

A total of 1203 children (aged 2-12) met our inclusion criteria and were recruited from oncology, orthopedic, and other departments of Zhengzhou Central Hospital, China. Of these, 390 were cases: 340 were diagnosed with ALL and remaining 50 were diagnosed with acute non-lymphoblastic leukemia. A total of 813 controls were recruited from the orthopedic department. Eighty-five percent of the cases were aged 2-6 years. The ratio of working mothers was similar in both the groups, and the socioprofessional category distribution was also similar in both the groups (Table 1). After correction for stratification of variable, good case control comparison of maternal and paternal schooling was obtained.

Table 1. Odds Ratios (OR) and 95\% confidence intervals (95\% CI) for parents' exposure to prioritized pesticides (i.e., those to which $>3$ cases had been exposed)-entries with $a \geq 1$ excess with a lower confidence limit of $<1$ ( $N=$ number of exposed cases).

\begin{tabular}{|c|c|c|c|c|c|c|c|c|c|c|c|c|c|c|}
\hline \multirow{4}{*}{ Pesticide } & \multicolumn{6}{|c|}{ Exposed versus unexposed } & \multicolumn{8}{|c|}{ High versus low exposure } \\
\hline & \multirow{3}{*}{$\mathrm{N}$} & \multicolumn{2}{|c|}{ Total leukaemia } & \multicolumn{3}{|c|}{ Childhood leukaemia } & \multicolumn{4}{|c|}{ Total leukaemia } & \multicolumn{4}{|c|}{ Childhood leukaemia } \\
\hline & & \multirow{2}{*}{ OR } & \multirow{2}{*}{$95 \% \mathrm{Cl}$} & \multirow{2}{*}{$\mathrm{N}$} & \multirow{2}{*}{ OR } & \multirow{2}{*}{$95 \% \mathrm{Cl}$} & \multicolumn{2}{|c|}{ Cases } & \multirow{2}{*}{$\begin{array}{l}\text { OR* } \\
\text { Low }\end{array}$} & \multirow{2}{*}{$95 \% \mathrm{Cl}$} & \multicolumn{2}{|l|}{ Cases } & \multirow[t]{2}{*}{$\mathrm{OR}^{*}$} & \multirow[t]{2}{*}{$95 \% \mathrm{Cl}$} \\
\hline & & & & & & & Low & High & & & High & & & \\
\hline \multicolumn{15}{|l|}{ Insecticides } \\
\hline \multicolumn{15}{|l|}{ Mothers } \\
\hline 1st year of childhood & 6 & 6.2 & $1.20-24.42$ & 6 & 6.4 & $1.2-29.32$ & 1 & 5 & $\infty \mathrm{b}$ & $\mathrm{b}$ & 1 & 5 & $\infty \mathrm{b}$ & $\mathrm{b}$ \\
\hline \multicolumn{15}{|l|}{ Herbicides } \\
\hline \multicolumn{15}{|l|}{ 2,4-D } \\
\hline \multicolumn{15}{|l|}{ Mothers } \\
\hline Years before conception & 12 & 1.2 & $0.3-2.45$ & 12 & 1.52 & $0.3-3.5$ & 3 & 9 & 5.21 & $1.23-34.71$ & 4 & 8 & 6.1 & $1.27-39.34$ \\
\hline
\end{tabular}




\begin{tabular}{|c|c|c|c|c|c|c|c|c|c|c|c|c|c|c|}
\hline 1st trimester & 8 & 2.33 & $0.12-8.22$ & 8 & 4 & $1.2-10.2$ & 3 & 5 & 3.3 & $0.3-33.4$ & 3 & 5 & 2.4 & $1.44-93.1^{\circ}$ \\
\hline 1st year of life & 12 & 1.2 & $0.3-1.44$ & 12 & 1.33 & $0.11-3.1$ & 2 & 8 & $12.4 \mathrm{c}$ & $1.4-93.41$ & 2 & 8 & $12.3 \mathrm{c}$ & $1.6-99$ \\
\hline \multicolumn{15}{|l|}{ Fungicides } \\
\hline \multicolumn{15}{|l|}{ Benomyl } \\
\hline \multicolumn{15}{|l|}{ Mothers } \\
\hline 1st year of life & 15 & 1.33 & $0.9-2.91$ & 12 & 1.7 & $0.4-10.0$ & 4 & 15 & 11 & $1.42-25.5$ & 3 & 4 & 8.3 & $1.2-32.3$ \\
\hline \multicolumn{15}{|l|}{ Validamycin } \\
\hline \multicolumn{15}{|l|}{ Mothers } \\
\hline 1st trimester & 11 & 1.21 & $0.6-5$ & 11 & 2.7 & $1.3-5$ & 4 & 8 & 2.22 & $0.3-12.4$ & 5 & 7 & 2.7 & $0.3-12.2$ \\
\hline
\end{tabular}

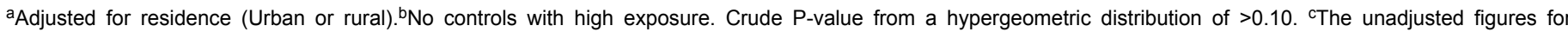
exposure to 2,4-D during the first year of life and low versus high exposures are OR 8.8 (95\% Cl 1.34-57).4 for total leukemia and OR 7.65 ( $95 \% \mathrm{Cl} 1.35-57.4)$ for acute lymphocytic leukemia.

Of all indexed children, only 2 cases and 3 controls had an occupational pesticide-exposed parent and only 2 cases and 1 control had an occupational pesticide-exposed mother during gestation (Figure 1). Therefore, data on occupational exposure to pesticides were not considered for final analysis.

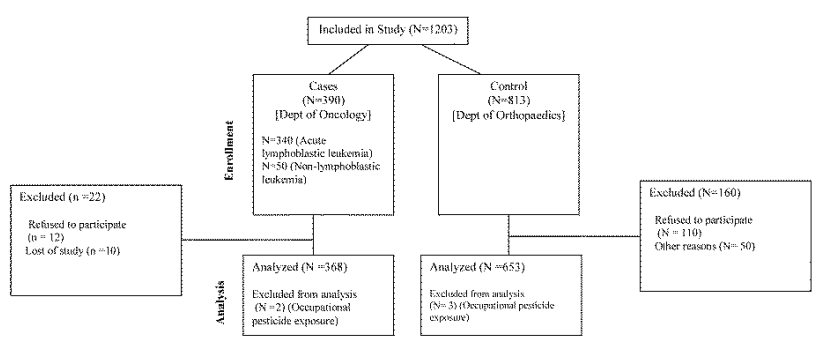

Figure 1. Consort flow chart depicting patient flow.

\section{Association between home insecticide use and childhood leukemia}

A substantial correlation was noted between childhood leukemia and home insecticide usage during pregnancy (OR $1.8,95 \%$ confidence interval $[\mathrm{CI}], 1.2-2.8)$ and during childhood (OR 1.3, 95\% CI [1.1-2.4]). Analysis of each exposure period separately demonstrated significant correlation between incidence of pediatric acute leukemia and exposure during gestation plus childhood but not during pregnancy (OR $2.3,95 \%$ CI $0.8-7.2$ ). A significant association was also found between incidence of pediatric leukemia and exposure during pregnancy but not during childhood (OR 1.23, 95\% CI 1.3-4.3). The occurrence of pediatric leukemia was also significantly higher in children exposed to pesticides only during childhood (OR 1.23, 95\% CI 1.1-2.7) (Table 2).

Table 2. Characteristics of the cases (childhood leukemia) and controls.

\begin{tabular}{|c|c|c|}
\hline 0 years & 4.1 & - \\
\hline $1-4$ years & 48.1 & - \\
\hline $5-9$ years & 35.2 & - \\
\hline \multicolumn{3}{|l|}{ Gender } \\
\hline Female & 40.1 & 50.11 \\
\hline Male & 60.1 & 50.2 \\
\hline \multicolumn{3}{|c|}{ Pesticides exposure while to pesticides } \\
\hline Maternal & 5 & 2.4 \\
\hline Paternal & 25.1 & 22.2 \\
\hline \multicolumn{3}{|l|}{ Leukaemia type } \\
\hline Acute lymphocytic leukaemia & 88.1 & - \\
\hline Acute non-lymphocytic leukaemia & 15.1 & - \\
\hline Other leukaemias & 2.4 & - \\
\hline \multicolumn{3}{|l|}{ Maternal age at conception } \\
\hline$<19$ & 10 & 11.2 \\
\hline $20-25$ years & 30.2 & 30.1 \\
\hline $26-30$ years & 29.1 & 25.1 \\
\hline $31-35$ years & 15.2 & 19.1 \\
\hline \multicolumn{3}{|l|}{ Maternal smoking during pregnancy } \\
\hline No & 96.2 & 95.2 \\
\hline Yes & 5.1 & 3.1 \\
\hline Missing & 1.22 & 0.4 \\
\hline \multicolumn{3}{|l|}{ Maternal alcohol during pregnancy } \\
\hline No & 95.1 & 94.11 \\
\hline Yes & 4.9 & 5.2 \\
\hline \multicolumn{3}{|l|}{ Socioeconomic status of familya } \\
\hline Low & 22.5 & 22 \\
\hline
\end{tabular}




\begin{tabular}{lll}
\hline Middle & 46.1 & 50 \\
\hline High & 10.22 & 11.1 \\
\hline Missing & 13.2 & 9.22 \\
\hline
\end{tabular}

aAssessed by interviewers with a form using various components-scored as low, medium, or high.

\section{Association between pesticide groups and $A L L$}

Effect estimates (single-group logistic regression model) for exposure to pesticides over the course of children's lifetime showed that moderate exposure to fumigants (OR 1.2, 95\% CI $0.7-2.4$ ) or insecticides (OR 1.2, 95\% CI 0.2-2.4) increased the risk of ALL in children (Table 3). However, there was not much difference in the estimates of ALL incidences between children highly exposed to insecticides or fumigants and controls. High or moderate exposure to pesticides within initial 12 months of life was not correlated with increased risk of ALL (Table 4).

\section{Effect of different variables on association}

The adjustments for different variables, including socioecomonic category, educational qualifications, place of residence (urban or rural), or type of home (flat or bungalow) of the parents, did not change the results. The effect estimate remained unchanged after grouping insecticide usage at home and gardening together. Separate or simultaneous adjustments for several factors that were previously found associated to increased likelihood of pediatric leukemia, such as family history of cancer or autoimmune diseases, repeated common infections early in childhood, extended suckling, day care attendance, and abode in the locality of a gasoline station or garage, did not change the results in this work. The results remained steady for all age groups and were similar for ALL.

Table 3. Odds ratios (OR) and 95\% confidence intervals (95\% CI) for total leukemia with respect to the mothers' exposure to pesticides to which $>3$ cases had been exposed, according to chemical group-exposed versus unexposed ( $N=$ number of exposed cases).

\begin{tabular}{|c|c|c|c|c|c|c|c|c|c|c|c|c|c|c|c|}
\hline \multirow{3}{*}{ Change } & \multicolumn{15}{|c|}{ Total leukaemia } \\
\hline & \multicolumn{3}{|c|}{ Year before conception } & \multicolumn{3}{|c|}{$1^{\text {st }}$ trimester } & \multicolumn{3}{|c|}{$2^{\text {nd }}$ trimester } & \multicolumn{3}{|c|}{$3^{\text {rd }}$ trimester } & \multicolumn{3}{|c|}{ First year of life } \\
\hline & $\mathrm{N}$ & $\mathrm{OR}^{\mathrm{a}}$ & $95 \% \mathrm{Cl}$ & $\mathrm{N}$ & $\mathrm{OR}^{\mathrm{a}}$ & $95 \% \mathrm{Cl}$ & $\mathrm{N}$ & $\mathrm{OR}^{\mathrm{a}}$ & $95 \% \mathrm{Cl}$ & $\mathrm{N}$ & $\mathrm{OR}^{\mathrm{a}}$ & $95 \% \mathrm{Cl}$ & $\mathrm{N}$ & $\mathrm{OR}^{\mathrm{a}}$ & $95 \% \mathrm{Cl}$ \\
\hline Organophosphates & 25 & 1.3 & $0.3-1.2$ & 12 & 0.4 & $0.4-1.42$ & 16 & 0.92 & $0.3-1.3$ & 20 & 1.3 & $0.61-1.22$ & 29 & 1 & $0.2-1.3$ \\
\hline Dithiocarbamates & 40 & 1.7 & $1.0-2.2$ & 30 & 1.3 & $0.7-.37$ & 13 & 1.4 & $0.5-2.4$ & 14 & 1.5 & $0.82-2.9$ & 21 & 1.2 & $0.5-2.7$ \\
\hline Pyrethroids & 24 & 1.5 & $0.8-2.3$ & 16 & 1.7 & 0.5 & 10 & 1.7 & $0.7-3.9$ & 11 & 1.8 & $0.6-3.9$ & 13 & 1 & $0.2-1.9$ \\
\hline Organochlorines & 16 & 0.9 & $0.6-2.8$ & 13 & 1.9 & $0.7-5.4$ & 7 & 1.8 & $0.7-4.2$ & 13 & 1.7 & $0.7-4.7$ & 10 & 1.4 & $0.6-3.1$ \\
\hline Triazines & 17 & 0.9 & $0.5-2.1$ & - & - & - & -- & - & - & 6 & 1.3 & $0.4-3.5$ & 8 & 1.3 & $0.5-2.7$ \\
\hline Chlorinated phthalides & 13 & 1.9 & $0.7-4.3$ & 7 & 2.7 & $0.9-9.1$ & 7 & 3.1 & $0.6-11$ & 5 & 2.2 & $0.6-11.1$ & 9 & 3.2 & $0.9-13$ \\
\hline Copper & 19 & 1.1 & $0.4-1.9$ & 5 & 1.2 & $0.4-2.5$ & 7 & 1.1 & $0.4-2.3$ & 7 & 0.9 & $0.5-2.8$ & 11 & 0.9 & $0.4-1.5$ \\
\hline Conazoles & 12 & 1.4 & $0.7-4.1$ & - & - & - & 5 & 2.3 & $0.7-2.1$ & 6 & 1.8 & $0.6-7.4$ & 13 & 1.1 & $0.8-3.9$ \\
\hline Carbamates & 16 & 1.3 & $0.6-2.4$ & 6 & 1.3 & $0.4-3.2$ & 9 & 1.8 & $0.4-4.0$ & 8 & 2 & $0.7-5.7$ & 14 & 1.3 & $0.5-2.3$ \\
\hline Benzimidines & 19 & 1.9 & $0.8-3.3$ & 15 & 2.2 & $1.0-4.5$ & 13 & 2.3 & $1.1-4.9$ & 12 & 2.2 & $1.0-5.3$ & 16 & 1.9 & $1.0-3.4$ \\
\hline Phenoxyacetic acids & 28 & 1.1 & $0.7-1.7$ & 14 & 0.8 & $0.5-1.9$ & 15 & 1.1 & $0.6-1.9$ & 20 & 1.3 & $0.9-1.7$ & 31 & 1.3 & $0.9-1.7$ \\
\hline Others $^{b}$ & 55 & 1.2 & $0.9-1.7$ & 40 & 1.3 & $0.7-1.8$ & 41 & 1.3 & $0.6-1.9$ & 39 & 1.5 & $0.5-1.3$ & 60 & 1.5 & $0.9-1.6$ \\
\hline
\end{tabular}

aAdjusted for residence (urban or rural). ${ }^{\text {b}}$ Adjusted for exposure to X-rays during pregnancy, in the 2nd trimester, and in the first year of life.

Table 4. Significant (lower $95 \%$ confidence limit $\geq 1.0$ ) excesses for either gender (unexposed versus exposed), $(N=$ number of exposed cases).

\begin{tabular}{|c|c|c|c|c|c|c|}
\hline \multirow{2}{*}{ Pesticides } & \multicolumn{3}{|c|}{ Boys } & \multicolumn{3}{|c|}{ Girls } \\
\hline & $\mathrm{N}$ & $\mathrm{OR}^{\mathrm{a}}$ & $95 \% \mathrm{Cl}$ & $\mathrm{N}$ & $\mathrm{OR}^{\mathrm{a}}$ & $95 \% \mathrm{Cl}$ \\
\hline \multicolumn{7}{|c|}{ Childhood leukaemia } \\
\hline Insecticides & & & & & & \\
\hline
\end{tabular}

Malathion, mothers

\begin{tabular}{|c|c|c|c|c|c|c|}
\hline Year before conception & 5 & 8.3 & $1.0-73.1$ & 3 & 1 & $0.3-4.7$ \\
\hline \multicolumn{7}{|l|}{ Herbicides } \\
\hline \multicolumn{7}{|l|}{ 2,4-D, Mothers } \\
\hline 1st trimester & 3 & 1.4 & $0.4-0.9$ & 7 & 4.7 & $1.3-20.2$ \\
\hline \multicolumn{7}{|l|}{ Fungicides } \\
\hline \multicolumn{7}{|l|}{ Benomyl, Mothers } \\
\hline Year before conception & 14 & 2.7 & $1.3-6.3$ & 5 & 0.8 & $0.5-3.1$ \\
\hline
\end{tabular}




\begin{tabular}{lcccccc}
\hline $1^{\text {st }}$ year & 13 & 3.1 & $1.5-8.1$ & 3 & 0.5 & $0.2-3.3$ \\
\hline \multicolumn{2}{l}{ Acute lymphocytic leukemia } & & & & & \\
\hline Insecticides & & & & & & \\
\hline Malathion, Mothers & & & & & & \\
\hline Year before conception & 7 & 11.6 & $1.3-93.1$ & 3 & 0.6 & $0.3-4.9$ \\
\hline Herbicides & & & & & & \\
\hline 2,4-D, Mothers & & & & & & \\
\hline $1^{\text {st }}$ trimester & 4 & 1.8 & $0.35-9.9$ & 5 & 5.6 & $1.3-24.6$ \\
\hline $1^{\text {st }}$ year of life & 4 & 0.7 & $0.19-2.9$ & 7 & 3 & $1.5-8.1$ \\
\hline Fungicides & & & & & & \\
\hline
\end{tabular}

Benomyl, Mothers

\begin{tabular}{lcccccc}
\hline Year before conception & 13 & 3.1 & $1.3-7.3$ & 5 & 1.2 & $0.5-2.9$ \\
\hline $1^{\text {st }}$ year of life & 12 & 3.6 & $1.2-8.6$ & 3 & 0.6 & $0.3-3.5$ \\
\hline Mancozeb, Mothers & & & & & & \\
\hline${ }^{\text {st }}$ trimester & 9 & 3.3 & $1.4-9.2$ & 5 & 1.3 & $0.5-3.7$ \\
\hline
\end{tabular}

aAdjusted for residence (urban or rural).

\section{Discussion}

Most cases of childhood leukemias are characterized by chromosomal abnormalities such as translocations, but very little information about their underlying cause is available. Very few studies in literature have illustrated a positive relationship between insecticide exposure during pregnancy and childhood and pediatric leukemia [14,15]. Ma et al. [16] reported a strong correlation between indoor pesticide usage and pediatric leukemia. They reported that the risk of childhood leukemia was higher in children whose mothers were exposed to pesticides. Additionally, the risk was higher when mothers were exposed to pesticides during pregnancy than those exposed prior to pregnancy or after parturition. Results suggested that families should be exceedingly deliberate about using indoor pesticides and women should be particularly cautious during childbearing age.

In a study performed by Lowengart et al. [17], a positive correlation was seen between childhood leukemia and exposure of mothers to garden herbicides or household pesticides during pregnancy, and the association remained after mutual adjustment. The study highlighted the necessity to lower prenatal and childhood exposure to pesticides and herbicides. However, the underlying mechanism of action and gene-pesticide interactions are not well understood and further studies are warranted to elucidate the association. Among residential pesticide studies that also recorded information on maternal exposure to occupational pesticides, the incidence of exposure was low and very little is known about its possible relationship with pediatric leukemia. A Philippine study evaluated the relationship between exposures to propoxur, a methylcarbamate insecticide, in agricultural areas. In subjects with detectable meconium levels of propoxur, the occurrence of translocation $(\mathrm{t}(8: 21))$, a common acute myeloid leukemia translocation, in cord blood was two times higher $[18,19]$. These studies suggest that it is important to acquire and critically review exposure information in future studies.

In this meta-analysis study, we aimed to provide further evidence to support the positive correlation between pesticide exposure and pediatric leukemia. We explored the involvement of parental occupational exposure to pesticides in causing pediatric leukemia and obtained complete data on residential pesticide exposure from parental reports. Only in few specific cases, we obtained detailed information or frequency of pesticide use. To minimize the error in exposure classification that can arise from use of only diagnosis or birth address and to distinguish exposure during a specific period, we integrated data from an ecological study in California that applied pesticide use reporting data [20]. The California-based study found that the occurrence of pediatric leukemia was highest in areas where herbicide propargite was used. The study used detailed residential histories as well as existing agriculture pesticide application data to focus on specific exposure time frame, improve the resolution of temporal and spatial variations in exposure assessment, and differentiate exposures between specific pesticides.

Our study had certain limitations. First, residential histories we obtained from mothers were not verified and therefore subject to recall error. The possibility of error was particularly high in older children who had no permanent residence and the earliest address preceded the interview by many years. Second, we had insufficient prenatal address history to evaluate exposure to agriculture pesticides during the gestational stage, which is the most crucial period because the risk is highest during this time [21]. Third, although we could determine the effects of pesticide exposure, segregated in terms of physicochemical properties, toxicity, and target pests, we did not have enough resources to estimate the response when the frequency of exposure was low. Our study showed that moderate exposure to different classes of agricultural pesticides, including insecticides, fumigants, possible carcinogens, reproductive toxins, genotoxins, endocrine disruptors, and anticholinesterase inhibitors, enhanced the likelihood of ALL in children. However, highest exposure did not increase the risk.

Our study revealed that pesticide exposure during pregnancy increased the likelihood of leukemia in children, and the strongest association was observed with insecticides. Additional studies are required to corroborate these findings as well as previous findings based on self-reporting. Future research should also focus on describing the exposure-response relationship with respect to specific subgroups pesticides in detail and evaluating the possible association between paternal pesticide exposure and pediatric leukemia.

\section{Acknowledgement}

The author would like to thank the staff and management of Henan Cancer Hospital, Henan Medical University No.1 
Affiliated Hospital and The Fifth Affiliated Hospital of Zhengzhou University, China for providing access to patients.

\section{References}

1. Torre LA, Sauer AM, Chen MS Jr., Kagawa-Singer M, Jemal A, Siegel RL. Cancer statistics for Asian Americans, Native Hawaiians, and Pacific Islanders, 2016: Converging incidence in males and females. CA Cancer J Clin 2016.

2. Edwards BK, Ward E, Kohler BA, Eheman C, Zauber AG, Anderson RN, Jemal A, Schymura MJ, Lansdorp-Vogelaar I, Seeff LC, van BM, Goede SL, Ries LA. Annual report to the nation on the status of cancer, 1975-2006, featuring colorectal cancer trends and impact of interventions (risk factors, screening, and treatment) to reduce future rates. Cancer 2010; 116: 544-573.

3. Malak CA, Elghanam DM, Elbossaty WF. FHIT Gene Expression in Acute Lymphoblastic Leukemia and its Clinical Significance. Asian Pac J Cancer Prev 2015; 16: 8197-8201.

4. Siegel RL, Miller KD, Jemal A. Cancer statistics, 2016. CA Cancer J Clin 2016; 66: 7-30.

5. Chen Y, Wang H, Kantarjian H, Cortes J. Trends in chronic myeloid leukemia incidence and survival in the United States from 1975 to 2009. Leuk Lymphoma 2013; 54: 1411-1417.

6. Dupuis LL, Lu X, Mitchell HR, Sung L, Devidas M, Mattano LA Jr., Carroll WL, Winick N, Hunger SP, Maloney KW, Kadan-Lottick NS. Anxiety, pain, and nausea during the treatment of standard-risk childhood acute lymphoblastic leukemia: A prospective, longitudinal study from the Children's Oncology Group. Cancer 2016.

7. Rossig C, Juergens H. Aetiology of childhood acute leukaemias: current status of knowledge. Radiat Prot Dosimetry 2008; 132: 114-118.

8. Buffler PA, Kwan ML, Reynolds P, Urayama KY. Environmental and genetic risk factors for childhood leukemia: appraising the evidence. Cancer Invest 2005; 23: 60-75.

9. Chen D, Zhang Y, Tian Y, Shi R, Wang X, Hu Y, Ji X, Han $\mathrm{K}$, Hu S, Mao S, Feng J, Gao Y. Relationship between risk of childhood acute leukemia and children's and parents' lifestyles and household environment exposure. Zhonghua Yu Fang Yi Xue Za Zhi 2015; 49: 792-799.

10. Lu C, Knutson DE, Fisker-Andersen J, Fenske RA. Biological monitoring survey of organophosphorus pesticide exposure among pre-school children in the Seattle metropolitan area. Environ Health Perspect 2001; 109: 299-303.

11. Daniels JL, Olshan AF, Savitz DA. Pesticides and childhood cancers. Environ Health Perspect 1997; 105: 1068-1077.

12. Infante-Rivard C, Weichenthal S. Pesticides and childhood cancer: an update of Zahm and Ward's 1998 review. J Toxicol Environ Health B Crit Rev 2007; 10: 81-99.
13. Zahm SH, Ward MH. Pesticides and childhood cancer. Environ Health Perspect 1998; 106: 893-908.

14. Buckley JD, Robison LL, Swotinsky R, Garabrant DH, LeBeau M, Manchester P, Nesbit ME, Odom L, Peters JM, Woods WG, . Occupational exposures of parents of children with acute nonlymphocytic leukemia: a report from the Childrens Cancer Study Group. Cancer Res 1989; 49: 4030-4037.

15. Alderton LE, Spector LG, Blair CK, Roesler M, Olshan AF, Robison LL, Ross JA. Child and maternal household chemical exposure and the risk of acute leukemia in children with Down's syndrome: a report from the Children's Oncology Group. Am J Epidemiol 2006; 164: 212-221.

16. Ma X, Buffler PA, Gunier RB, Dahl G, Smith MT, Reinier K, Reynolds P. Critical windows of exposure to household pesticides and risk of childhood leukemia. Environ Health Perspect 2002; 110: 955-960.

17. Lowengart RA, Peters JM, Cicioni C, Buckley J, Bernstein L, Preston-Martin S, Rappaport E. Childhood leukemia and parents' occupational and home exposures. J Natl Cancer Inst 1987; 79: 39-46.

18. Lafiura KM, Bielawski DM, Posecion NC Jr., Ostrea EM, Jr., Matherly LH, Taub JW, Ge Y. Association between prenatal pesticide exposures and the generation of leukemia-associated T(8;21). Pediatr Blood Cancer 2007; 49: 624-628.

19. Raimondi SC, Chang MN, Ravindranath Y, Behm FG, Gresik MV, Steuber CP, Weinstein HJ, Carroll AJ. Chromosomal abnormalities in 478 children with acute myeloid leukemia: clinical characteristics and treatment outcome in a cooperative pediatric oncology group studyPOG 8821. Blood 1999; 94: 3707-3716.

20. Reynolds P, Von BJ, Gunier RB, Goldberg DE, Hertz A, Harnly ME. Childhood cancer and agricultural pesticide use: an ecologic study in California. Environ Health Perspect 2002; 110: 319-324.

21. Birnbaum LS, Fenton SE. Cancer and developmental exposure to endocrine disruptors. Environ Health Perspect 2003; 111: 389-394.

\section{*Correspondence to:}

Chun-Mei Yu

Department of Pediatrics

Maternal and Child Health Care of Zaozhuang

Shandong province,

PR China 